\title{
Surveying pulsating auroras
}

\author{
Eric Grono and Eric Donovan \\ Department of Physics and Astronomy, University of Calgary, Calgary, Alberta, Canada
}

Correspondence: Eric Grono (emgrono@ucalgary.ca)

Received: 28 August 2019 - Discussion started: 6 September 2019

Accepted: 26 November 2019 - Published: 2 January 2020

\begin{abstract}
The early-morning auroral oval is dominated by pulsating auroras. These auroras have often been discussed as if they are one phenomenon, but they are not. Pulsating auroras are separable based on the extent of their pulsation and structuring into at least three subcategories. This study surveyed 10 years of all-sky camera data to determine the occurrence probability for each type of pulsating aurora in magnetic local time and magnetic latitude. Amorphous pulsating aurora (APAs) are a pervasive, nearly daily feature in the early-morning auroral oval which have an $86 \%$ chance of occurrence at their peak. Patchy pulsating auroras (PPAs) and patchy auroras (PAs) are less common, peaking at $21 \%$ and $29 \%$, respectively. Before local midnight, pulsating auroras are almost exclusively APAs. Occurrence distributions of APAs, PPAs, and PAs are mapped into the equatorial plane to approximately locate their source regions. The PA and PPA distributions primarily map to locations approximately between 4 and $9 R_{\mathrm{E}}$, while some APAs map to farther distances, suggesting that the mechanism which structures PPAs and PAs is constrained to the inner magnetosphere. This is in agreement with Grono and Donovan (2019), which located these auroras relative to the proton aurora.
\end{abstract}

\section{Introduction}

If one looks at the aurora for just a few hours, it is obvious that there are different types. If one looks at enough auroras, it becomes apparent that a relatively small number of specific auroral types dominate the overall phenomenon. Historically, early auroral researchers classified auroras based on their appearance. This morphological classification lacks any connection to the magnetospheric or magnetosphere-ionosphere coupling mechanisms that might cause a specific type of aurora.
More recently, auroral types have been considered with regard to the physical drivers of these processes, and great headway has been made differentiating them based on the mechanism responsible for their particle precipitation. In the broadest sense, there are two types of mechanism corresponding to two overarching auroral classifications. In some auroras, electric fields parallel to the magnetic field - socalled parallel electric fields - increase particles' kinetic energy parallel to the magnetic field, shifting their pitch angle into the loss cone. Such auroras are classified as discrete, an example of which is the auroral arc. In other auroras, stochastic interactions with plasma waves or magnetic field curvature scatter particles' pitch angles into the loss cone. In these cases, the aurora is classified as diffuse.

Pulsating auroras are a type of diffuse aurora characterized by quasi-periodic pulsations and precipitating electron energies between a few kiloelectron volts and hundreds of kiloelectron volts (Johnstone, 1978). They generally have an irregular, patchy structure (Royrvik and Davis, 1977) which constantly evolves in time (Shiokawa et al., 2010). The spatial size of pulsating auroral structures has been measured to range from one to hundreds of kilometres across (Royrvik and Davis, 1977). Measurements of pulsating aurora altitude thicknesses are scarce, but Jones et al. (2009) measured a pulsating auroral patch and found it to be between 15 and $25 \mathrm{~km}$ thick.

Pulsating aurora events occur most often in the morning sector, when they persist for an average of $1.5 \mathrm{~h}$ (Jones et al., 2011; Partamies et al., 2017), but events lasting upwards of $15 \mathrm{~h}$ have been observed (Jones et al., 2013). It is unknown exactly how long pulsating aurora events can persist for. Measurements of pulsating aurora event durations are conservative because ground-based cameras, our primary tool for optically observing the aurora, cannot operate past sunrise (Partamies et al., 2017). The lifetimes of individual 
structures are known to range from a few seconds to tens of minutes (e.g., Grono et al., 2017; Grono and Donovan, 2018).

Pulsating auroral features exhibit diverse characteristics, varying in terms of shape, size, brightness, altitude, spatial stability, modulation, lifespan, and velocity, yet little effort has been spent on differentiating them. Historically, pulsating auroras were subcategorized by Royrvik and Davis (1977) into patches, arcs, and arc segments, but modern literature generally only refers to "pulsating aurora" and "pulsating auroral patches" (e.g., Yang et al., 2019; Partamies et al., 2019; Ozaki et al., 2019) and would not consider the "streaming arc" of Royrvik and Davis (1977) to be a type of pulsating aurora. Grono and Donovan (2018) recently used all-sky camera data to define criteria for differentiating pulsating aurora based on their phenomenology. They identified three types of pulsating aurora which were separable based on their pulsation and structure. Amorphous pulsating auroras (APAs) evolve so rapidly in both shape and brightness that it is usually difficult - and often impossible - to uniquely identify structures between successive images at a 3 s cadence. Patchy pulsating auroras (PPAs) consist of highly structured patches which can persist for tens of minutes and pulsate over much of their area. Patchy aurora (PA) structures are similar to those of PPAs but do not oscillate in brightness. While it may be oxymoronic to describe a non-pulsating feature as pulsating aurora, PAs and PPAs are clearly closely related in terms of the underlying scattering mechanism responsible for the precipitation. Based on their appearance in the ionosphere, these two auroras seem to be differentiated only by the existence of a modulating mechanism in the magnetospheric source region. Herein we use the term "pulsating aurora" to collectively refer to APAs, PPAs, and PAs, and the acronyms will be used to identify them individually.

Pulsating auroras have been shown to be pervasive in the morning sector (Jones et al., 2011; Partamies et al., 2017), but we believe those studies conflated at least APAs and PPAs, while possibly ignoring PAs altogether due to their relative lack of pulsation (Grono and Donovan, 2018). Nishimura et al. $(2010,2011)$ connected specific examples of APAs and PPAs, without differentiating them, with specific chorus elements in the equatorial magnetosphere. Yang et al. (2015, 2017) related the individual motion of PPA and PA patches to convection in the ionosphere, and their source regions to convection in the magnetosphere. Yang et al. (2019) observed one event where an APA feature was associated with higherenergy electron precipitation than a PPA patch. By locating the latitude boundaries of pulsating auroras relative to the proton aurora, Grono and Donovan (2019) discovered that they occur either within or equatorward of the proton aurora. PPAs and PAs were observed to occur predominantly equatorward of the optical b2i (Donovan et al., 2003), which is the ionospheric counterpart to the isotropy boundary for plasma sheet protons and marks the inner boundary of the thin current sheet. APAs also occurred there, but in addition, it regularly extended into the transition region where the band of proton aurora luminosity originates from and the magnetic field is stretched.

The aurora is a powerful tool for remote sensing the largescale dynamics of the magnetosphere. Pulsating auroras are a widespread type of aurora, the subcategories of which we do not yet understand. This gap in our collective knowledge limits the information about the state of magnetosphere that can be inferred from pulsating aurora. While surveys of pulsating aurora have been done previously (Jones et al., 2011; Partamies et al., 2017), they have not distinguished between different types. This study presents the first separate surveys of occurrence probabilities for APAs, PPAs, and PAs.

\section{Data and methodology}

To survey pulsating aurora occurrence, the Time History of Events and Macroscale Interactions during Substorms (THEMIS) all-sky imager (ASI) array was used. This network of imagers (Donovan et al., 2006; Mende et al., 2008) is the ground-based component of the NASA mission (Angelopoulos, 2008) designed to study the aurora and substorms using conjoined ground-based and space-borne observations. The ASIs capture panchromatic, or "white light", images of the aurora at a $3 \mathrm{~s}$ cadence on a $256 \times 256$ pixel charge-coupled device (CCD) and have been operating for over 10 years, amassing tens of millions of images. It can be surmised from Jones et al. (2011) that pulsating auroras are visible within about $10 \%$ of these images (Grono et al., 2017). Of the 21 imagers deployed across North America, those stationed at Rankin Inlet, Nunavut (RANK); Gillam, Manitoba (GILL); and Pinawa, Manitoba (PINA) were utilized for this study. The locations and fields of view of these imagers are shown in Fig. 1. The fields of view are drawn at $10^{\circ}$ of elevation relative to the imager at an altitude of $110 \mathrm{~km}$.

Data from these ASIs were viewed as keogram-style images (Eather et al., 1976) illustrating the evolution of aurora in time and one spatial dimension, which in this case was aligned to the Gillam magnetic meridian at $-26.1089^{\circ} \mathrm{mag}-$ netic longitude (MLON). These keograms, an example of which is shown in Fig. 2, were arranged and aligned in a stack to give a wide view of the aurora along this meridian so that the upper and lower magnetic latitude boundaries of pulsating auroral events could be identified. The location of this meridian relative to the fields of view of the ASIs can be seen in Fig. 1.

Across 2006 through 2016, 280 d were identified where visibility was simultaneously clear at all three sites. Keograms were created for each day of data to search for pulsating aurora. To ensure that the start and end times could be identified precisely and that short periods of pulsating aurora would not be missed, dates were split into multiple $1 \mathrm{~h}$ sized keograms. However, in general, there was not an inte- 


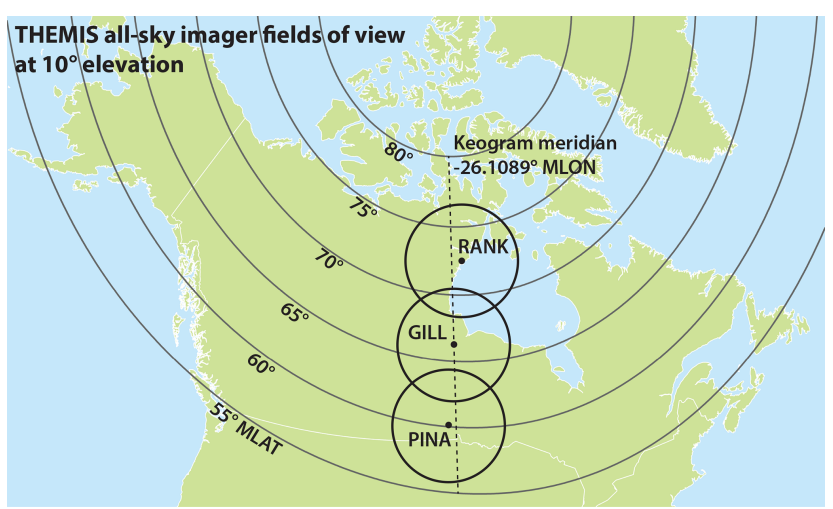

Figure 1. The locations and fields of view of the three THEMIS ASIs utilized in this study. The imagers are located in Rankin Inlet, Nunavut; Gillam, Manitoba; and Pinawa, Manitoba. The fields of view are drawn at $10^{\circ}$ elevation assuming an altitude of $110 \mathrm{~km}$.

ger number of hours of clear data, so each day also had one shorter keogram containing the remaining data.

Within each keogram, the upper and lower latitude boundaries as well as the start and end times of pulsating aurora events were identified by eye and recorded. One spatial dimension does not necessarily provide enough information to accurately define the boundaries of pulsating aurora, but it provides a reasonable estimate when the alternative is to define the boundaries for hundreds of thousands of individual ASI images. This simple method of defining the event boundaries is often imprecise since the size of the region which pulsating auroras cover can change, in addition to its location. Multiple sets of boundaries were often used to better define where pulsating auroras were occurring within the keograms in order to compensate. Despite this limitation, more precise and accurate methods of defining the event boundaries are prohibitively time consuming for a dataset of this size.

The latitude and temporal boundaries were recorded separately for APAs, PPAs, and PAs, which is illustrated in Fig. 2. This sample image from the dataset features colour-coded rectangles marking where each pulsating aurora type was identified.

To identify the boundaries of each type, certain characteristic features are searched for. PPAs and PAs move with ionospheric convection (Yang et al., 2015, 2017; Grono et al., 2017; Grono and Donovan, 2018) and have a stable, welldefined structure that creates pathlines in keograms. Pathlines trace the trajectory of PPA and PA patches along the keogram meridian and arise due to the long-lived nature of PPA and PA patches. These are the primary signature used for identifying PPAs and PAs in keograms. Since PA patches do not pulsate, they are separable from PPAs by the presence of vertical striations within the pathline which are indicative of pulsation. The appearance of APAs within keograms cannot be described as simply, but they are primarily identified by vertical striations and a lack of a well-defined structure.

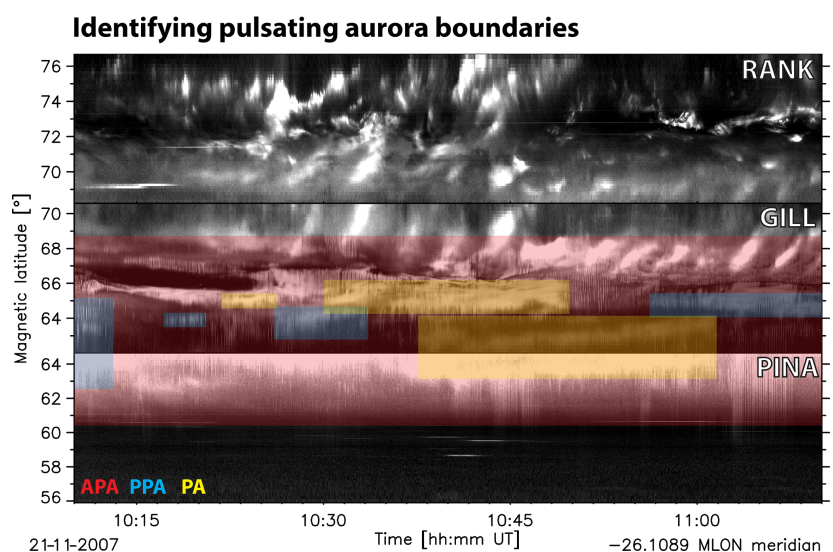

Figure 2. An example of a keogram used to approximately define pulsating aurora occurrence. The regions where amorphous pulsating auroras (APAs, red), patchy pulsating auroras (PPAs, blue), and patchy auroras (PAs, yellow) can be identified in the keogram are marked with rectangles. The meridian that the keograms are aligned along is illustrated in Fig. 1.

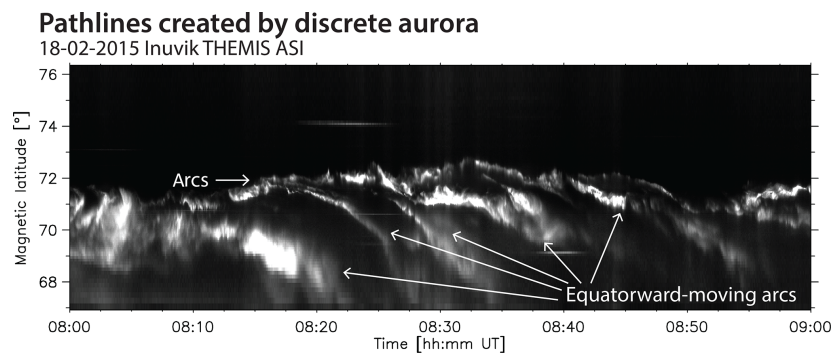

Figure 3. An example of equatorward arcs creating multiple pathlines that move in the same direction. These images were captured by the THEMIS ASI stationed in Inuvik, Nunavut, on 18 February 2015.

Based on this, it is generally straightforward to uniquely identify each type of pulsating aurora within keograms (Grono and Donovan, 2018), but certain events can be ambiguous and in these instances the full all-sky images were inspected. Occasionally it can be unclear whether an event consists of APAs or PPAs. This can be due to a lack spatial information provided by the keogram-style image, but it can also be hard to distinguish between APAs that are atypically structured and PPAs that are relatively unstructured. Since PPA and PA events will feature many patches, the presence of multiple pathlines can be a helpful indicator for recognizing these auroras. PPAs and PAs move with convection, so the pathlines of multiple patches will have similar trajectories within an event. In addition, APAs seem to be present during every pulsating aurora event (Grono and Donovan, 2018), so their presence is a helpful indicator when searching for PPAs and PAs. The nature of the relationship between these three types of pulsating aurora is unclear, and gradation appears to 
exist between them (Grono and Donovan, 2018), which can complicate identification.

Pathlines are not exclusive to pulsating auroral patches, however, as arcs can also produce them, as seen in Fig. 3. Auroral events featuring multiple equatorward-moving arcs will produce multiple pathlines which move in the same direction. Despite the apparent similarity of such structuring to that of PPAs and PAs, they are distinguishable from each other with practice.

\section{Results}

We searched 10 years of clear auroral observations, and in Fig. 4 we present separate distributions of occurrence probability for each type of pulsating aurora in magnetic local time (MLT) and magnetic latitude (MLAT). These occurrence probabilities are calculated by dividing the number of days a particular type was observed in a bin by its number of days of clear observations. The number of hours of data of each pulsating aurora type that went into Fig. $4 \mathrm{a}-\mathrm{c}$ are $462 \mathrm{~h}$ of APAs, $44 \mathrm{~h}$ of PPAs, and $58 \mathrm{~h}$ of PAs, respectively. These totals are not exact because they are a sum of the time spans each set of boundaries covered, which can overlap. This can be seen in Fig. 2, where two PA regions overlap in time. Overlapping boundaries are not so common as to dominate this calculation and as such these totals are reasonable estimates of the amount of observations. Figure $4 d$ shows the number of days each MLT bin was observed, and within each of these the coverage of the MLAT bins is uniform since our event selection required clear visibility across each ASI.

APAs are seen in Fig. 4a occurring in a band from 17 to 7 MLT between 56 and $75^{\circ}$ MLAT, peaking during 3.5 to $6 \mathrm{MLT}$ at 66 to $70^{\circ}$ MLAT with an $\sim 86 \%$ probability. This band appears wider at later MLT. Figure $4 \mathrm{~b}$ shows PPAs predominantly arising in a band from 23 to 6.5 MLT over 57 to $73^{\circ}$ MLAT, and to a much lesser extent between 17.5 to 19.5 MLT when the bins are populated by only a single day of data. PPA occurrence probability peaks at $\sim 21 \%$ from 4 to 5.5 MLT between 65 to $67^{\circ}$ MLAT. PAs are shown in Fig. 4c to occur in a band stretching from 23 to 7 MLT between 59 and $74^{\circ}$ MLAT. The peak occurrence probability of PAs is $\sim 29 \%$ between 4 to 5.5 MLT from 65 to $66^{\circ}$ MLAT. The latitude of the PA occurrence band is less obviously dependent on magnetic local time than the other pulsating auroras in these data. This is possibly due to having fewer observations of PPAs and PAs, which each have on the order of $10 \%$ of the observations that APAs have. PPAs and PAs occur in a narrower band than APAs. The range of latitudes where pulsating auroras can develop evolves over MLT, following the same trend as the auroral oval, moving to higher latitude with increasing distance from local midnight.

In Fig. 4, the peak activities of each of the three types of pulsating aurora appear to differ in both MLT and MLAT, but they are difficult to compare when plotted separately as two-

\section{When and where pulsating auroras form}

(a) Amorphous pulsating aurora (462 h)

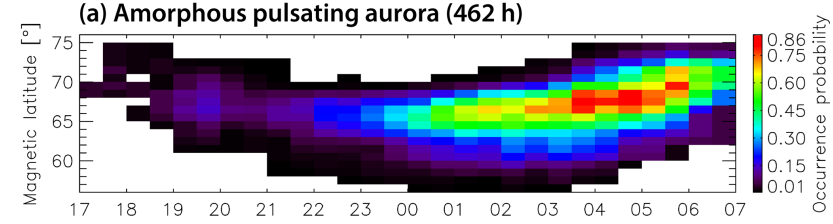

(b) Patchy pulsating aurora (44 h)

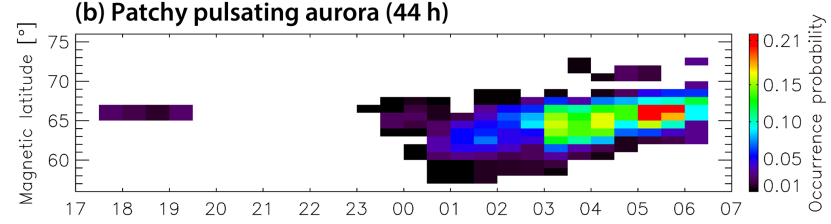

(c) Patchy aurora (58 h)

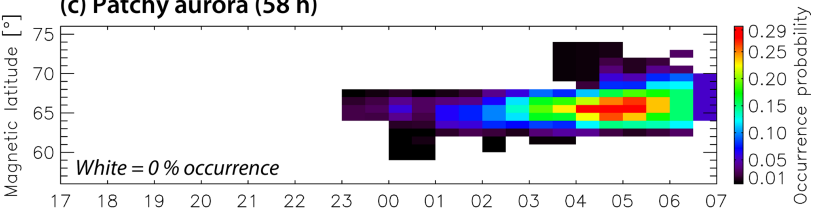

(d) Dataset MLT coverage (280 d from 2006-2016)

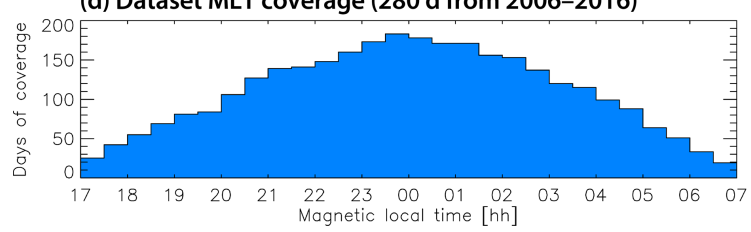

Figure 4. Occurrence probability of pulsating auroras based on a survey of times when Rankin Inlet, Gillam, and Pinawa THEMIS ASI had good visibility between 2006 through 2016. White bins in panels (a), (b), and (c) have data coverage but no events, corresponding to a $0 \%$ occurrence probability. Panel (d) shows the number of days of data that had clear visibility in each MLT bin and coverage is uniform across the MLAT bins.

dimensional histograms. Figure 5 reduces Fig. $4 \mathrm{a}-\mathrm{c}$ to two separate one-dimensional histograms in MLT and MLAT, allowing the occurrence distributions to be more easily compared. Figure 5a shows that APAs cover a larger range of latitudes than PPAs and PAs, extending farther poleward than both. PPAs appear to develop nearly as far equatorward as APAs, although PAs do not. Furthermore, the peak occurrence of APAs appears to be 1 to $2^{\circ}$ MLAT poleward of PPAs and PAs. In Fig. 5b, PPAs and PAs have similar MLT distributions whose peaks approximately align with a local maximum of APAs that is $\sim 3 \mathrm{~h}$ later than its peak.

\section{Discussion and conclusions}

The latitude and temporal boundaries of pulsating auroras that were recorded during the survey provide sets of coordinates which can be traced into the equatorial plane of the magnetosphere to estimate the location of their source regions. In this context, a set of boundaries refers to any individual rectangular region used to define the occurrence of pulsating auroras within a keogram, such as those seen in 

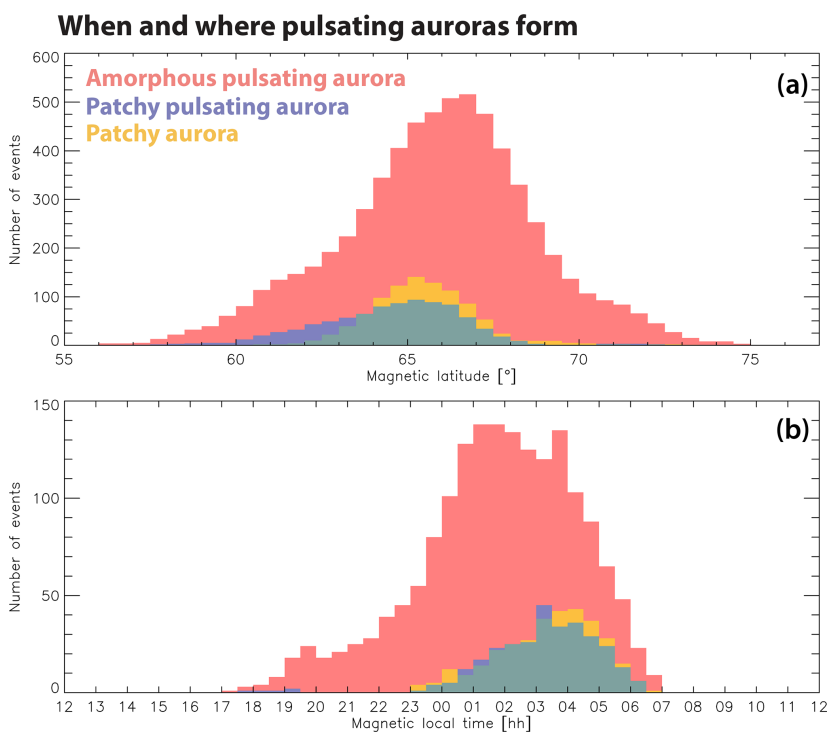

Figure 5. Figure 4 reduced in dimension to separate histograms in MLT and MLAT to allow easier comparison of occurrence between the types of pulsating aurora.

Fig. 2. Since a set of boundaries can cover long periods of time and therefore correspond to a large region in the equatorial plane, we split each set into 1 min slices to more accurately map the shape of its source region. The start and end times of each set were rounded down to the nearest minute, and the latitude boundaries were mapped into the equatorial plane at each minute in between.

Figure 6 shows distributions counting the number of boundaries - that is, the rectangles in Fig. 2 - that intersect with $1 R_{\mathrm{E}}$ by $1 R_{\mathrm{E}}$ bins when mapped into the magnetosphere using the T89 magnetic model (Tsyganenko, 1989). These bins are in the $X Y$ geocentric solar magnetospheric (GSM) equatorial plane where the $Z$ GSM component of the magnetic field changes from being directed away from Earth to toward it. Each boundary is mapped at a 1 min time resolution to ensure its shape in the equatorial plane accurately reflects changing geomagnetic conditions.

The T89 model was given the planetary K-index $(\mathrm{Kp})$ and the $X$ component of solar wind velocity in geocentric solar wind velocity in geocentric solar ecliptic (GSE) coordinates. Newer models were tested, but the mapped distributions did not meaningfully change. The purpose of mapping the occurrence distributions is to estimate the average location of the source regions, rather than accurately trace individual events. To this end, the decreased computation time of the T89 model was deemed more valuable than an increase in accuracy which had little impact on the distributions.

Figure 6 does not show a mapping of the occurrence probability, but merely where the events were located. As stated previously, the purpose of this figure is only to approximately locate the source regions of pulsating auroras. Fewer events are used to create the panels in Fig. 6 than Figs. 4 and 5, be- cause events were ignored if at least $90 \%$ of the solar wind velocity data was made up of bad data; otherwise the bad data were replaced with values interpolated from the valid data points. According to Fig. 6, PPAs and PAs predominantly originate from a region between roughly 4 and $9 R_{\mathrm{E}}$. Before local midnight, APAs are similarly constrained, however, a portion of the APA distribution maps beyond $9 R_{\mathrm{E}}$ after midnight. If you ignore the lowest population bins, it extends as far out as approximately $15 R_{\mathrm{E}}$.

These distributions are in agreement with Grono and Donovan (2019), which reported PPAs and PAs being constrained to more equatorward latitudes than APAs relative to the proton aurora. The bright band of auroral luminosity created by proton precipitation is known as "the proton aurora". Proton precipitation occurs when the pitch angles of magnetically trapped protons are scattered as the particles pass through tight magnetic field curvature in the equatorial plane (Tsyganenko, 1982; Sergeev et al., 1983). The earthward limit of this stochastic scattering mechanism is the isotropy boundary (e.g., Sergeev et al., 1983), which is located where the magnetic field transitions from being stretched to mostly dipolar. There is an equivalent boundary in the ionosphere, called the optical b2i (Donovan et al., 2003), which marks the rapid decrease of downgoing proton fluxes. Grono and Donovan (2019) found that all pulsating aurora occurred either within or equatorward of the proton aurora. PPAs and PAs occurred predominantly equatorward of the optical b2i, indicating that they originate from a region where magnetic field topology is mostly dipolar. APAs were seen poleward of the optical b2i, but still within the proton aurora.

We know that the proton auroras occur primarily along and tailward of the transition region between dipolar and stretched magnetic fields, and that it occurs at higher latitudes further from local midnight. However, observations of the bright proton aurora's source region have been limited to near magnetic midnight. Spanswick et al. (2017) related the luminosity of the proton aurora to in situ downward proton energy fluxes measured by THEMIS spacecraft in the magnetotail near midnight. They determined that the source regions of most proton auroras were located between 6 and $10 R_{\mathrm{E}}$ at this time, although some could map beyond this. Interpreting this distance range as the farthest limit of pulsating aurora in the equatorial plane near magnetic midnight (Grono and Donovan, 2019), our observations are in agreement.

Global distributions of lower-band whistler-mode chorus (Li et al., 2011), a primary driver of pulsating aurora (e.g., Nishimura et al., 2010, 2011), also indicate that these are realistic distributions of the pulsating aurora source regions. Li et al. (2011) reported lower-band chorus occurrence primarily between 5 and $\sim 8 R_{\mathrm{E}}$ near magnetic midnight, and a wider occurrence region after midnight between 5 and $10 R_{\mathrm{E}}$. They only surveyed events between 5 and $10 R_{\mathrm{E}}$, the most dominant region for lower-band chorus.

APAs area a pervasive early-morning auroral phenomenon which dominate the morning-sector auroral oval and occur 
Pulsating aurora occurrence mapped to the equatorial plane
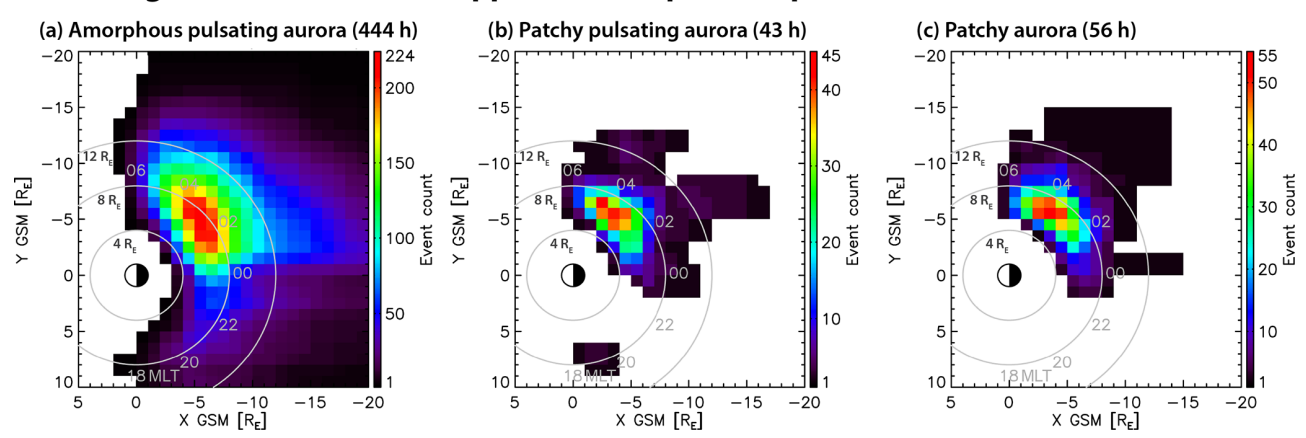

Figure 6. Pulsating aurora occurrence mapped to the equatorial plane. Pulsating aurora time and latitude boundaries were mapped using the T89 model (Tsyganenko, 1989) given Kp and the solar wind velocity GSE $X$ component. This figure is based on the same set of events as shown in Fig. 4, excluding those with poor solar wind data.

nearly every day. Pulsating auroras are almost exclusively APAs between 17 and 23 MLT, during which time PPAs were seen on a single day and PAs were never seen. APAs are the most common type of pulsating aurora, occurring as often as $\sim 86 \%$ of the time between 3.5 and 6 MLT. PPA and PA occurrences peak at $\sim 21 \%$ between 5 and 6 MLT and $\sim 29 \%$ from 4 to $5.5 \mathrm{MLT}$, respectively. APAs extend farther poleward than PPAs and PAs, and farther equatorward than PAs. The range of latitudes where pulsating auroras can exist varies with MLT, following the auroral oval and reaching its most equatorward latitude at $\sim 2$ MLT.

These results are in agreement with recent work by Jones et al. (2011) and Partamies et al. (2017), which reported pulsating aurora occurrence statistics. We suspect that both of these studies included a combination of APAs and PPAs in their statistics and likely ignored PAs. The prevalence of APAs indicates that their results should largely reflect the behaviour of APAs. Jones et al. (2011) examined 119d of optical data from the Gillam THEMIS ASI between September 2007 and March 2008, finding that the occurrence rate of pulsating aurora events increases rapidly around magnetic midnight from a small percentage to roughly $50 \%$. Occurrence increased to nearly $60 \%$ around 3 MLT and remained high until camera shutdown. The APA distribution in Fig. 4a is smoother and more strongly peaked than that of Jones et al. (2011), and this is likely attributable to our larger dataset. A precise comparison between the number of hours is not possible since Jones et al. (2011) only indicated the number of dates their data covered. Compared to our PPA and PA distributions, their occurrence rate is too high and has too early and wide of a peak to likely correspond to a type other than APAs. With this consideration in mind, we report a higher peak chance of occurrence than Jones et al. (2011). However, they suggested that their result may be lower relative to past studies by Kvifte and Pettersen (1969) and Oguti et al. (1981) due to the influence of the solar cycle. In contrast, our dataset covers almost an entire solar cycle.
Partamies et al. (2017) surveyed 10 years of optical data from five imagers as part of the Magnetometers-Ionospheric Radars All-sky Cameras Large Experiment (MIRACLE) network of all-sky cameras (Syrjäsuo et al., 1998; Sangalli et al., 2011) between 1997 and 2007. While they did not publish an occurrence probability distribution, they did report that the peak occurrence was between approximately 4 and 7 MLT. Without an occurrence rate to compare to, it is difficult to conclude they predominantly observed APAs, but PPAs and PAs do have a narrower peak in MLT than this. A stipulation of our dataset is that all three ASIs must simultaneously have clear visibility, so our data do not continue past the shutdown time of the lowest-latitude camera in Pinawa. The MIRACLE cameras stationed in Lapland that Partamies et al. (2017) analyzed were not similarly constrained and could continue observing later, plausibly explaining why their peak persisted until 7 MLT.

It is unknown which specific mechanisms and conditions are involved in each of these types of pulsating aurora, but structural similarity between PAs and PPAs (Grono and Donovan, 2018) indicates that they are differentiated only by the existence of modulating processes in the source region. This suggests that pulsation and structuring are the two fundamental aspects of pulsating aurora phenomenology. APAs can begin to appear much earlier than PPAs and PAs, occurrence peaks earlier, and they seem to be the only type that can constitute an entire pulsating auroral event on its own (Grono and Donovan, 2018).

The occurrence distributions of APAs, PPAs, and PAs were mapped into the equatorial plane of the magnetosphere. These mappings correspond to the average locations of their source regions, and they agree with observations reported by other studies. PPAs and PAs are predominantly constrained between 4 and $\sim 9 R_{\mathrm{E}}$, while a portion of the APA distribution maps beyond this, as far out as $\sim 15 R_{\mathrm{E}}$.

Moving forward, there are three key questions pertaining to the conditions and mechanisms driving pulsating auroras: what processes are responsible for the structuring of PPAs 
and PAs, why do PAs not pulsate, and do APAs play a role in the onset of PPAs and PAs?

Data availability. The complete set of Fig. 2-style images for the entire dataset is available in Grono (2019, https://doi.org/10.5683/SP2/MICSLT). THEMIS ASI data are available from http://data.phys.ucalgary.ca/sort_by_project/ THEMIS/asi/stream0/ (last access: 16 December 2019). Planetary K-index data were retrieved from the National Oceanic and Atmospheric Administration Space Weather Prediction Center at ftp://ftp.swpc.noaa.gov/pub/indices/old_indices/ (last access: 16 December 2019). Solar wind velocity was obtained via Operating Missions as Nodes on the Internet (OMNI, https://omniweb.gsfc.nasa.gov/ow.html, last access: 16 December 2019).

Author contributions. EG programmed, analyzed the data, and wrote the work and designed the figures. ED is his supervisor and assisted with analysis.

Competing interests. The authors declare that they have no conflict of interest.

Acknowledgements. Thanks to Emma Spanswick, Harald Frey, and Stephen Mende for all-sky data from the NASA Time History of Events and Macroscale Interactions during Substorms (THEMIS) mission.

Financial support. This research was supported by the Canadian Space Agency and Government of Canada (grant no. 13SUGOAGO).

Review statement. This paper was edited by Georgios Balasis and reviewed by two anonymous referees.

\section{References}

Angelopoulos, V.: The THEMIS Mission, Space Sci. Rev., 141, 534, https://doi.org/10.1007/s11214-008-9336-1, 2008.

Donovan, E., Mende, S., Jackel, B., Frey, H., Syrjäsuo, M., Voronkov, I., Trondsen, T., Peticolas, L., Angelopoulos, V., Harris, S., Greffen, M., and Connors, M.: The THEMIS allsky imaging array - system design and initial results from the prototype imager, J. Atmos. Sol.-Terr. Phy., 68, 1472-1487, https://doi.org/10.1016/j.jastp.2005.03.027, 2006.

Donovan, E. F., Jackel, B. J., Voronkov, I., Sotirelis, T., Creutzberg, F., and Nicholson, N. A.: Ground-based optical determination of the b2i boundary: A basis for an optical MT-index, J. Geophys. Res.-Space, 108, 1115, https://doi.org/10.1029/2001JA009198, 2003.
Eather, R. H., Mende, S. B., and Judge, R. J. R.: Plasma injection at synchronous orbit and spatial and temporal auroral morphology, J. Geophys. Res., 81, 2805-2824, https://doi.org/10.1029/JA081i016p02805, 1976.

Grono, E.: Replication data for: Surveying Pulsating Auroras, Scholars Portal Dataverse, https://doi.org/10.5683/SP2/MICSLT, 2019.

Grono, E. and Donovan, E.: Differentiating diffuse auroras based on phenomenology, Ann. Geophys., 36, 891-898, https://doi.org/10.5194/angeo-36-891-2018, 2018.

Grono, E. and Donovan, E.: Constraining the Source Regions of Pulsating Auroras, Geophys. Res. Lett., 46, 10267-10273, https://doi.org/10.1029/2019GL084611, 2019.

Grono, E., Donovan, E., and Murphy, K. R.: Tracking patchy pulsating aurora through all-sky images, Ann. Geophys., 35, 777-784, https://doi.org/10.5194/angeo-35-777-2017, 2017.

Johnstone, A. D.: Pulsating aurora, Nature, 274, 119-126, https://doi.org/10.1038/274119a0, 1978.

Jones, S. L., Lessard, M. R., Fernandes, P. A., Lummerzheim, D., Semeter, J. L., Heinselman, C. J., Lynch, K. A., Michell, R. G., Kintner, P. M., Stenbaek-Nielsen, H. C., and Asamura, K.: PFISR and ROPA observations of pulsating aurora, J. Atmos. Sol.-Terr. Phy., 71, 708-716, https://doi.org/10.1016/j.jastp.2008.10.004, 2009.

Jones, S. L., Lessard, M. R., Rychert, K., Spanswick, E., and Donovan, E.: Large-scale aspects and temporal evolution of pulsating aurora, J. Geophys. Res.-Space, 116, A03214, https://doi.org/10.1029/2010ja015840, 2011.

Jones, S. L., Lessard, M. R., Rychert, K., Spanswick, E., Donovan, E., and Jaynes, A. N.: Persistent, widespread pulsating aurora: A case study, J. Geophys. Res.-Space, 118, 2998-3006, https://doi.org/10.1002/jgra.50301, 2013.

Kvifte, G. J. and Pettersen, H.: Morphology of the pulsating aurora, Planet. Space Sci., 17, 1599-1607, https://doi.org/10.1016/00320633(69)90148-2, 1969.

Li, W., Bortnik, J., Thorne, R. M., and Angelopoulos, V.: Global distribution of wave amplitudes and wave normal angles of chorus waves using THEMIS wave observations, J. Geophys. Res.Space, 116, A12205, https://doi.org/10.1029/2011JA017035, 2011.

Mende, S. B., Harris, S. E., Frey, H. U., Angelopoulos, V., Russell, C. T., Donovan, E., Jackel, B., Greffen, M., and Peticolas, L. M.: The THEMIS Array of Ground-based Observatories for the Study of Auroral Substorms, Space Sci. Rev., 141, 357-387, https://doi.org/10.1007/s11214-008-9380-x, 2008.

Nishimura, Y., Bortnik, J., Li, W., Thorne, R. M., Lyons, L. R., Angelopoulos, V., Mende, S. B., Bonnell, J. W., Le Contel, O., Cully, C., Ergun, R., and Auster, U.: Identifying the Driver of Pulsating Aurora, Science, 330, 81-84, https://doi.org/10.1126/science.1193186, 2010.

Nishimura, Y., Bortnik, J., Li, W., Thorne, R. M., Chen, L., Lyons, L. R., Angelopoulos, V., Mende, S. B., Bonnell, J., Le Contel, O., Cully, C., Ergun, R., and Auster, U.: Multievent study of the correlation between pulsating aurora and whistler mode chorus emissions, J. Geophys. Res.-Space, 116, A11221, https://doi.org/10.1029/2011JA016876, 2011.

Oguti, T., Kokubun, S., Hayashi, K., Tsuruda, K., Machida, S., Kitamura, T., Saka, O., and Watanabe, T.: Statistics of pulsating auroras on the basis of all-sky TV data from five sta- 
tions. I. Occurrence frequency, Can. J. Phys., 59, 1150-1157, https://doi.org/10.1139/p81-152, 1981.

Ozaki, M., Miyoshi, Y., Shiokawa, K., Hosokawa, K., Oyama, S.-i., Kataoka, R., Ebihara, Y., Ogawa, Y., Kasahara, Y., Yagitani, S., Kasaba, Y., Kumamoto, A., Tsuchiya, F., Matsuda, S., Katoh, Y., Hikishima, M., Kurita, S., Otsuka, Y., Moore, R. C., Tanaka, Y., Nosé, M., Nagatsuma, T., Nishitani, N., Kadokura, A., Connors, M., Inoue, T., Matsuoka, A., and Shinohara, I.: Visualization of rapid electron precipitation via chorus element wave-particle interactions, Nat. Commun., 10, 257, https://doi.org/10.1038/s41467-018-07996-z, 2019.

Partamies, N., Whiter, D., Kadokura, A., Kauristie, K., Nesse Tyssøy, H., Massetti, S., Stauning, P., and Raita, T.: Occurrence and average behavior of pulsating aurora, J. Geophys. Res.Space, 122, 5606-5618, https://doi.org/10.1002/2017JA024039, 2017.

Partamies, N., Bolmgren, K., Heino, E., Ivchenko, N., Borovsky, J. E., and Sundberg, H.: Patch Size Evolution During Pulsating Aurora, J. Geophys. Res.-Space, 124, 4725-4738, https://doi.org/10.1029/2018JA026423, 2019.

Royrvik, O. and Davis, T. N.: Pulsating aurora - Local and global morphology, J. Geophys. Res., 82, 4720-4740, https://doi.org/10.1029/JA082i029p04720, 1977.

Sangalli, L., Partamies, N., Syrjäsuo, M., Enell, C. F., Kauristie, K., and Mäkinen, S.: Performance study of the new EMCCDbased all-sky cameras for auroral imaging, Int. J. Remote Sens., 32, 2987-3003, https://doi.org/10.1080/01431161.2010.541505, 2011.

Sergeev, V. A., Sazhina, E. M., Tsyganenko, N. A., Lundblad, J. A., and Soraas, F.: Pitch-angle scattering of energetic protons in the magnetotail current sheet as the dominant source of their isotropic precipitation into the nightside ionosphere, Planet. Space Sci., 31, 1147-1155, https://doi.org/10.1016/00320633(83)90103-4, 1983.
Shiokawa, K., Nakajima, A., Ieda, A., Sakaguchi, K., Nomura, R., Aslaksen, T., Greffen, M., and Donovan, E.: Rayleigh-Taylor type instability in auroral patches, J. Geophys. Res.-Space, 115, A02211, https://doi.org/10.1029/2009JA014273, 2010.

Spanswick, E., Donovan, E., Kepko, L., and Angelopoulos, V.: The Magnetospheric Source Region of the Bright Proton Aurora, Geophys. Res. Lett., 44, 10094-10099, https://doi.org/10.1002/2017GL074956, 2017.

Syrjäsuo, M., Pulkkinen, T. I., Janhunen, P., Viljanen, A., Pellinen, R. J., Kauristie, K., Opgenoorth, H. J., Wallman, S., Eglitis, P., Karlsson, P., Amm, O., Nielsen, E., and Thomas, C.: Observations of Substorm Electrodynamics Using the MIRACLE Network, in: Substorms-4, edited by: Kokubun, S. and Kamide, Y., Vol. 238 of Astrophysics and Space Science Library, p. 111, 1998.

Tsyganenko, N. A.: Pitch-angle scattering of energetic particles in the current sheet of the magnetospheric tail and stationary distribution functions, Planet. Space Sci., 30, 433-437, https://doi.org/10.1016/0032-0633(82)90052-6, 1982.

Tsyganenko, N. A.: A magnetospheric magnetic field model with a warped tail current sheet, Planet. Space Sci., 37, 5-20, https://doi.org/10.1016/0032-0633(89)90066-4, 1989.

Yang, B., Donovan, E., Liang, J., Ruohoniemi, J. M., and Spanswick, E.: Using patchy pulsating aurora to remote sense magnetospheric convection, Geophys. Res. Lett., 42, 5083-5089, https://doi.org/10.1002/2015GL064700, 2015.

Yang, B., Donovan, E., Liang, J., and Spanswick, E.: A statistical study of the motion of pulsating aurora patches: using the THEMIS All-Sky Imager, Ann. Geophys., 35, 217-225, https://doi.org/10.5194/angeo-35-217-2017, 2017.

Yang, B., Spanswick, E., Liang,, J., Grono, E., and Donovan, E.: Responses of Different Types of Pulsating Aurora in Cosmic Noise Absorption, Geophys. Res. Lett., 46, 5717-5724, https://doi.org/10.1029/2019GL083289, 2019. 